\title{
A Road to Excellence: The History of Basic Nursing Education at the University Hospital of the West Indies, Jamaica, 1949-2006
}

Claire Duncan, Valerie Hardware, Jean Munroe, Norma Woodham

This is an excellent history book for nurse educators in Jamaica, as a substantial amount of it addresses conditions that existed in nursing education and interventions that have moved nursing to be on par with the world as it is now. For the older reader, it offers nostalgic moments and allows for comparison of their past with the present time. Much has been changed, and one would be fascinated with the glimpses of the primitive role of the nurse and, more so, the ever-evolving, indomitable curriculum of nurses' education.

The book is divided into seven chapters. Opening with early $17^{\text {th }}$ century nursing education in Jamaica, the book progresses down through the $18^{\text {th }}, 19^{\text {th }}, 20^{\text {th }}$ and finally to the $21^{\text {st }}$ century. Overall, it offers a journey that is unique to the nursing profession in Jamaica.

It is the changing structure which governs the training that the authors seek to focus on as they travel through a period of observation, on-the-job training, apprenticeship and finally into an institution with formal required qualification and period of training. The progress ended in 2006 with the last batch of students at University Hospital School of Nursing being grandfathered to become the first batch for the University of the West Indies School of Nursing. The authors were all nurses and served in different capacities in the school and/or hospital.

Medical doctors and other medical personnel would also appreciate this journey as milestones that are common are shared, such as the establishment of the teaching hospital (now University Hospital of the West Indies) which served as training ground for both doctors and nurses. With the establishment of the hospital, nursing education moved into a more formalized curriculum and continued to be fine-tuned to reflect that of its overseas counterpart.

As the history unfolds, the reader will discover that the journey is not completely linear. In fact, the second chapter begins and completes the journey through highlights from international, national and local events that impacted the development of the basic nursing education. It could be considered introductory, but its details would force the reader to return to it time and time again to grasp a fuller picture of a location, function or varying activities. However, when the book is completed, the parts coalesce.
The core of it, chapters 3-6, outlines the specifics/features common to the basic education programmes during the varying stages of transition. These include areas such as the programme structure, teaching methodologies, assessments, programme evaluations, and administration.

The organization of the core may pose a challenge if the reader is comparing contents of subheadings of each time frame. The information under certain headings may not be consistent and may lead the reader to feel that certain activities were not present during a particular time frame. However, if the reader continues reading, he or she will see the comparative information listed under another subheading.

The anecdotes listed at the back of the book will bring much laughter to the reader and remind the young at heart as well as other groups of youthful pranks. The presentation of this archival work would be better enhanced by the insertion of some of these anecdotes into the time frames. Among other extraordinary listings that the appendices concluded with are visits from overseas medical and nursing students, and individuals honoured through the graduations over the years. The selected bibliography provides a rich source for obtaining more information.

There are some areas that could be improved in the book. The structure is a little unpolished. The final chapter would be better as an appendix since each 'highlight' depicts persons on the journey who were already featured at points where their services were mentioned. Nevertheless, the book provides a valuable and absorbing entrance into the past of nursing education in Jamaica, particularly at the University Hospital of the West Indies. If it had not been written, it would have been an inestimable loss, as at the time of writing this review, most of the writers had already ended their earthly mission.

\author{
HM Ming \\ Director, Nursing Staff Development \\ University Hospital of the West Indies \\ Kingston 7, Jamaica, West Indies \\ hilda.ming@uhwi.gov.jm
}

